Case Report

\title{
Inferior Dislocation of Shoulder Complicated with Undisplaced Greater Tuberosity Fracture, Rupture of the Supraspinatus Tendon, and Brachial Plexus Injury in the Elderly: Case Report and Literature Review
}

\author{
Angelo V. Vasiliadis $\mathbb{D}^{1,2}$ Christos Kalitsis, ${ }^{1}$ Theofanis Kantas, ${ }^{1}$ and George Biniaris ${ }^{1}$ \\ ${ }^{1}$ Department of Orthopaedic Surgery, General Hospital of Katerini, Katerini, Greece \\ ${ }^{2}$ School of Medicine, Aristotle University of Thessaloniki, Thessaloniki, Greece \\ Correspondence should be addressed to Angelo V. Vasiliadis; vasiliadis.av@gmail.com
}

Received 10 June 2019; Accepted 22 May 2020; Published 1 June 2020

Academic Editor: George Mouzopoulos

Copyright (C) 2020 Angelo V. Vasiliadis et al. This is an open access article distributed under the Creative Commons Attribution License, which permits unrestricted use, distribution, and reproduction in any medium, provided the original work is properly cited.

\begin{abstract}
Inferior dislocation of the shoulder, also called luxatio erecta, is a rare form of the otherwise common shoulder dislocation. It appears in less than $0.5 \%$ of all shoulder dislocations. An awareness of associated potential axillary artery injury, brachial plexus complications, and rotator cuff tears is important in this rare entity and should be excluded with a high index of suspicion. In our case report, we have an 83-year-old female who inferiorly dislocated her dominant shoulder with brachial plexus injury and musculotendinous injury, which was caused by an accidental fall. The dislocation was manually reduced at the emergency department. After 18 months of conservative treatment with physical therapy, the range of motion and muscle strength of the shoulder recovered to a satisfactory mobile level according to the patient's demands.
\end{abstract}

\section{Introduction}

The shoulder joint is a highly mobile, but inherently unstable one and involves articulation between the head of the humerus and the glenoid fossa of the scapula, which enables a wide range of movements including forward flexion, abduction, adduction, external/internal rotation, and $360^{\circ}$ circumduction [1]. Shoulder dislocation is a common dislocation found in $45 \%$ of all large joint dislocations treated in an Emergency Department (ED). Inferior shoulder dislocation, also known as "luxatio erecta", is a relatively rare form of glenohumeral dislocations in the $\mathrm{ED}$, found in only $0.5 \%$ of all shoulder dislocations $[1,2]$. Typically, the patient presents with the arm locked in an upright position [3]. Inferior shoulder dislocation is frequently associated with injuries to the static and/or dynamic stabilizers, fracture of the greater tuberosity, and can potentially be complicated with neurovascular deficit. Immediate close reduction is required to avoid neurovascular complications. A careful neurovascular examination is mandatory, both before and after closed reduction [1]. The aim of this case report is to describe an inferior shoulder dislocation with peripheral nerve injury and also give an overview regarding the neural deficit of inferior shoulder dislocation which is described in the literature.

\section{Case Report}

An 83-year-old woman came to the emergency department with a complaint of shoulder pain and incapacity to lower her arm after an accidental fall from the last step of her home staircase. According to her own report, she had put her right arm outstretched above the level of her head, in the opposite wall, causing hyperflexion of the shoulder, in order to avoid the impact of a head injury. At that moment, she experienced numbness and shock-like electrical sensations in the fingers of the ipsilateral hand. In addition, there was a clear medical history without previous shoulder dislocation or contributing pathologies. 


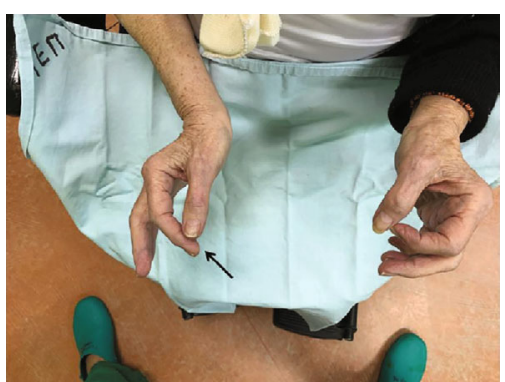

Figure 1: Injury of the anterior interosseous nerve with difficulty in performing the "OK" sign (black arrow).

On physical examination, her dominant arm was abducted at the shoulder and flexed at the elbow. The patient could not adduct the arm to less than $80^{\circ}$. Examination revealed loss of contour of shoulder and presence of the head of humerus palpable in the axilla. Vascular function was not compromised in the affected extremity, as verified through the presence of radial pulse. However, she presented a deficit attempting the "OK" sign and a positive digit abduction/adduction test, which characterizes an injury to the anterior interosseous nerve (branch of the median nerve) (Figure 1) and ulnar nerve, respectively.

Radiographic examination confirmed the clinical diagnosis of a complete inferior dislocation of the humeral head lying beneath the glenoid cavity, without any accompanying fracture (Figure 2(a)). Immediate reduction was done with intravenous analgesia-sedation by in-line traction-abduction and gently pushing the humeral head superiorly, while countertraction was provided by an assistant. An audible pop was heard when the humeral head was reduced (Figure 2(b)). The delay between the time of injury and reduction was 2 hours. After successfully closed reduction, the right shoulder was immobilized using an arm sling. Following reduction, the deficit in attempting the "OK" sign and digit abductio$\mathrm{n} /$ adduction test remained. The patient was discharged under instructions to maintain the immobilization (elbow to body) for three weeks to allow soft tissue healing.

A magnetic resonance imaging (MRI) of the shoulder was carried out ten days later in order to evaluate softtissue structures, such as the rotator cuff and labrum, and occult skeletal pathology. The MRI revealed a Bankart lesion in the anteroinferior aspect of the glenoid labrum of the shoulder. A bone marrow contusion line in the greater tuberosity of the humerus showed a contusion-crank fracture without displacement. A complete rupture of the supraspinatus tendon was also revealed (Figure 3). Although the patient was advised to treat the rotator cuff rupture surgically, she chose not to do so. Further evaluation by an electromyography study revealed the destruction of the myelin sheath of the median nerves bilaterally (carpal tunnel syndrome). In addition, the altered dynamics of the right median and ulnar nerves could be related to neurapraxia due to the nerve compression.

After three weeks, physical therapy was proposed with gentle pendulum movements of the injured upper limb. Passive range of motion and isometric deltoid exercises was proposed during the $4^{\text {th }}$ and $6^{\text {th }}$ weeks, respectively. After the $8^{\text {th }}$

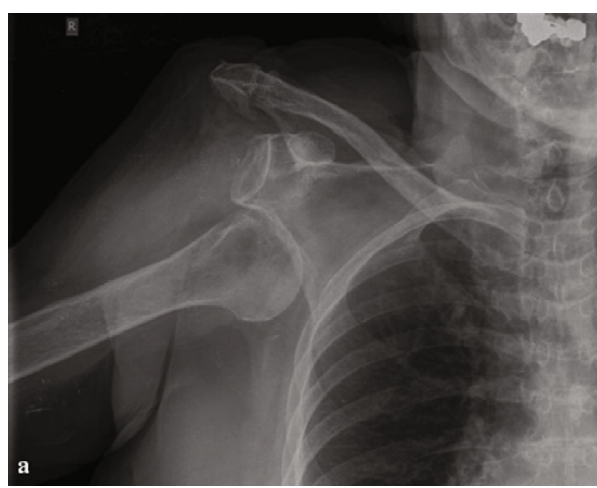

(a)

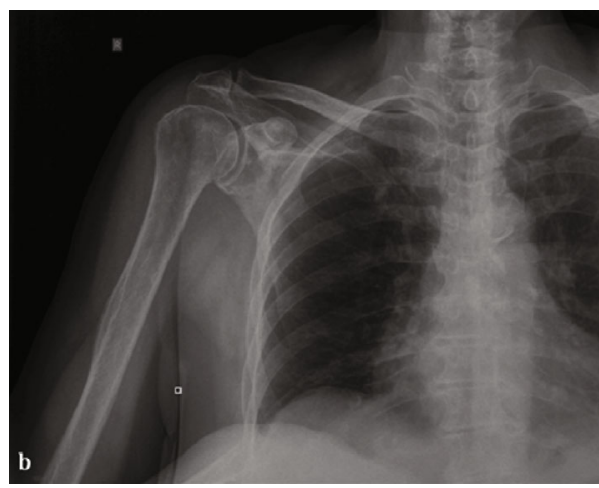

(b)

FIgURE 2: Anteroposterior (AP) radiographic view of the right shoulder shows a humeral head out of the glenoid fossa lying inferior to the glenoid rim (a). Postreduction AP radiographic view shows congruent reduction (b).

week, active/strengthening exercises were proposed. After 6 months of the reduction, the patient had a mild weakness in the little finger, with difficulty to abduct her arm above the head (over $100^{\circ}$ ). Shoulder function was assessed, and the Constant score was 69 out of 100 points. At 18 months, the patient regained a nearly full active range of motion in the shoulder and had no instability toward elevation or rotation. At the present time point, she is satisfied with her function and she is independent and able to perform activities of daily living. The Constant score was 81 out of 100 points.

\section{Discussion}

The current case report highlights the need for awareness of the potential nerve damage following inferior shoulder dislocation and also highlights what it is known from the literature. Inferior shoulder dislocation is a rare injury and has been determined in the literature comprising only $0.5 \%$ of all shoulder dislocations with no age predilection, but with male predominance [4]. Two mechanisms of injury have been described for inferior shoulder dislocation. First, an indirect mechanism of the injury involves a sudden and forceful hyperabduction to an already abducted arm $[5,6]$. The second mechanism of injury involves direct axial loading on a fully abducted arm with the elbow extended and forearm pronated [7-9]. Table 1 shows the etiology and mechanisms 


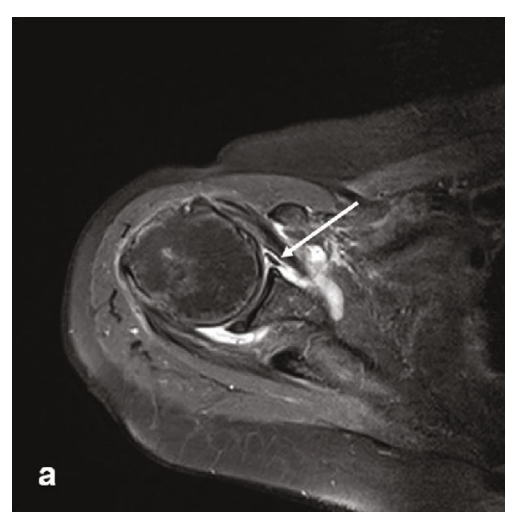

(a)

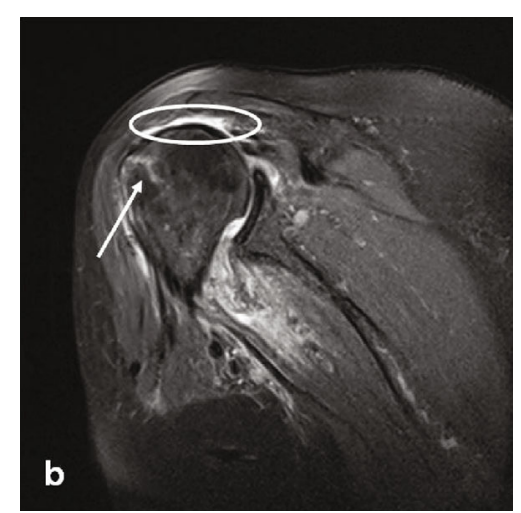

(b)

FIgure 3: A transverse (a) T2-weighted MRI view shows a Bankart lesion (white arrow) of the right shoulder. A coronal (b) T2-weighted MRI view shows a bone marrow contusion line associated with a contusion-crack fracture without displacement of the greater tuberosity of the humerus (white arrow) and a complete rupture of the supraspinatus tendon (white circle).

TABLE 1: Etiology and mechanism of injuries (literature review and present study).

\begin{tabular}{|c|c|c|c|c|c|}
\hline Study & Gender $(\mathrm{M} / \mathrm{F})$ & Age (Y) & Side, U/B ( ${ }^{\circ}$ blocked) & Etiology of injury & Mechanism of injury \\
\hline Present study, 2020 & $\bar{F}$ & 83 & $\mathrm{U}\left(80^{\circ}\right)$ & Fall from height & Direct \\
\hline Kaziz et al., 2018 & $\mathrm{~F}$ & 23 & $\mathrm{U}$ & Sport related & Direct \\
\hline Yao et al., 2018 & M & 40 & $\mathrm{U}\left(170^{\circ}\right)$ & Fall from height & Indirect \\
\hline \multirow{2}{*}{ Demirtas et al., 2017} & $\mathrm{~F}$ & 80 & $\mathrm{U}\left(130^{\circ}\right)$ & Pedestrian (vs. vehicle) & Direct \\
\hline & M & 34 & $\mathrm{U}\left(120^{\circ}\right)$ & Fall & Direct \\
\hline Fox and Martin, 2016 & M & 58 & $\mathrm{~B}$ & Fall from height & Indirect \\
\hline Owen et al., 2016 & M & 30 & $\mathrm{U}\left(170^{\circ}\right)$ & MBA & Direct \\
\hline Acosta et al., 2015 & M & 43 & $\mathrm{~B}\left(110^{\circ}\right)$ & Fall from height & Direct \\
\hline Cift et al., 2015 & M & 65 & $\mathrm{U}$ & MVA & $\mathrm{N} / \mathrm{R}$ \\
\hline Petty et al., 2014 & M & 68 & B & Sport related (treadmill) & Indirect \\
\hline Ellanti et al., 2013 & M & 19 & B & MVA & $\mathrm{N} / \mathrm{R}$ \\
\hline \multirow{2}{*}{ Imerci et al., 2013} & M & 50 & $\mathrm{U}$ & MBA & $\mathrm{N} / \mathrm{R}$ \\
\hline & $\mathrm{F}$ & 51 & $\mathrm{U}$ & Fall & $\mathrm{N} / \mathrm{R}$ \\
\hline \multirow{7}{*}{ Groh et al., 2010} & M & 17 & $\mathrm{U}$ & $\mathrm{MBA}$ & $\mathrm{N} / \mathrm{R}$ \\
\hline & M & 17 & $\mathrm{U}$ & Sport related (bull riding) & $\mathrm{N} / \mathrm{R}$ \\
\hline & M & 60 & $\mathrm{U}$ & MBA & $\mathrm{N} / \mathrm{R}$ \\
\hline & M & 27 & $\mathrm{U}$ & MBA & $\mathrm{N} / \mathrm{R}$ \\
\hline & M & 17 & $\mathrm{U}$ & Sport related (basketball) & $\mathrm{N} / \mathrm{R}$ \\
\hline & M & 40 & $\mathrm{~B}$ & Fall from height & $\mathrm{N} / \mathrm{R}$ \\
\hline & $\mathrm{F}$ & 18 & $\mathrm{U}$ & MVA & $\mathrm{N} / \mathrm{R}$ \\
\hline Camarda et al., 2009 & $\mathrm{~F}$ & 70 & $\mathrm{U}$ & Fall & Indirect \\
\hline Sharma and Denolf, 2004 & M & 69 & $\mathrm{U}$ & Fall & Direct \\
\hline Kumar et al., 2001 & M & 58 & $\mathrm{~B}\left(100^{\circ}\right)$ & Fall & $\mathrm{N} / \mathrm{R}$ \\
\hline Grate, 2000 & M & 20 & $\mathrm{U}\left(110^{\circ}\right)$ & Sport related (wrestling) & Direct \\
\hline Davids and Talbott, 1990 & M & 29 & $\mathrm{U}$ & Sport related (roller skate) & Indirect \\
\hline Rae and Sylvester, 1988 & $\mathrm{~F}$ & 34 & $\mathrm{U}$ & Sport related (tennis) & Indirect \\
\hline
\end{tabular}

Abbreviations: M: male; F: female; Y: years; U: unilateral; B: bilateral; MBA: motorbike accident; MVA: motor vehicle accident; N/R: not reported.

of injury after a review of the literature. The most common etiologies of such injury are falls, followed by sports-related injuries, motorbike, and motor vehicle accidents (Table 1).

Clinically, the patient will present with an abducted extremity, which will be unable to lower. The elbow is flexed and the forearm pronated. The hand is often resting on, or next to, the head $[10,11]$. The average reported abduction of the humerus is $120^{\circ}\left(80^{\circ}-170^{\circ}\right)$ on clinical assessment at presentation $[3,8,11,16,20]$. Closed reduction is typically performed either by manual manipulation of "traction- 
TABLE 2: A summary of the literature review and the present study, on the nerve injury and associated injuries of inferior shoulder dislocation.

\begin{tabular}{|c|c|c|c|c|c|c|c|}
\hline Study & $\begin{array}{l}\text { Gender } \\
(\mathrm{M} / \mathrm{F})\end{array}$ & $\begin{array}{l}\text { Age } \\
(\mathrm{Y})\end{array}$ & $\begin{array}{l}\text { Side, U/B } \\
\text { ( }{ }^{\circ} \text { blocked) }\end{array}$ & Nerve injury & $\begin{array}{c}\text { Nerve deficit } \\
\text { (postreduction) }\end{array}$ & $\begin{array}{c}\text { Associated } \\
\text { injuries }\end{array}$ & $\begin{array}{c}\text { F-U } \\
\text { (months) }\end{array}$ \\
\hline Present study, 2020 & $\mathrm{~F}$ & 83 & $\mathrm{U}\left(80^{\circ}\right)$ & Medial/ulnar nerve & Ulnar nerve & GTF, RCT & 18 \\
\hline Kaziz et al., 2018 & $\mathrm{~F}$ & 23 & $\mathrm{U}$ & Axillary nerve & None & GTF & 10 \\
\hline Yao et al., 2018 & M & 40 & $\mathrm{U}\left(150^{\circ}\right)$ & Axillary nerve & None & GTF & 8 \\
\hline \multirow{2}{*}{ Demirtas et al., 2017} & $\mathrm{~F}$ & 80 & $\mathrm{U}\left(130^{\circ}\right)$ & Radial/median/ulnar nerve & None & None & 26 \\
\hline & M & 34 & $\mathrm{U}\left(120^{\circ}\right)$ & Radial nerve & None & GTF & 28 \\
\hline Fox and Martin, 2016 & M & 58 & B & Axillary nerve (sensory) & None & $\begin{array}{l}\text { GTF, RCT, } \\
\text { OEF }\end{array}$ & 6 \\
\hline Owen et al., 2016 & M & 30 & $\mathrm{U}\left(170^{\circ}\right)$ & Brachial plexus (3 cords) & $\begin{array}{l}\text { Median/ulna nerves } \\
\text { (sensory) }\end{array}$ & GTF, RCT & 24 \\
\hline Acosta et al., 2015 & M & 43 & $\mathrm{~B}\left(110^{\circ}\right)$ & Radial nerve & Radial nerve (motor) & GTF & 60 \\
\hline Cift et al., 2015 & M & 65 & $\mathrm{U}$ & Radial paresthesia & None & None & 22 \\
\hline Petty et al., 2014 & M & 68 & $\mathrm{~B}$ & Numbness C6-C8 (hand) & $\mathrm{N} / \mathrm{R}$ & None & $\mathrm{N} / \mathrm{R}$ \\
\hline Ellanti et al., 2013 & M & 19 & $\mathrm{~B}$ & $\begin{array}{c}\text { Paraesthesia C6-C7, radial } \\
\text { nerve }\end{array}$ & None & GTF & 6 \\
\hline \multirow{2}{*}{ Imerci et al., 2013} & M & 50 & $\mathrm{U}$ & Axillary nerve & None & None & 27 \\
\hline & $\mathrm{F}$ & 51 & $\mathrm{U}$ & Brachial plexus & None & None & 25 \\
\hline \multirow{7}{*}{ Groh et al., 2010} & M & 17 & $\mathrm{U}$ & Radial/median/ulnar nerve & None & None & 12 \\
\hline & M & 17 & $\mathrm{U}$ & Ulnar nerve & None & None & 264 \\
\hline & M & 60 & $\mathrm{U}$ & Axillary nerve & None & GTF & 24 \\
\hline & M & 27 & $\mathrm{U}$ & Axillary/radial nerve & None & RCT & 180 \\
\hline & M & 17 & $\mathrm{U}$ & Axillary nerve & None & None & 36 \\
\hline & M & 40 & B & Axillary nerve & $\begin{array}{l}\text { Axillary nerve } \\
\text { (paresis) }\end{array}$ & None & 40 \\
\hline & $\mathrm{F}$ & 18 & $\mathrm{U}$ & Axillary/radial nerve & None & None & 32 \\
\hline Camarda et al., 2009 & $\mathrm{~F}$ & 70 & $\mathrm{U}$ & Paraesthesia C5-T1 & None & None & 12 \\
\hline $\begin{array}{l}\text { Sharma and Denolf, } \\
2004\end{array}$ & M & 69 & $\mathrm{U}$ & Paraesthesia SCNF & None & GTF & 6 \\
\hline Kumar et al., 2001 & M & 58 & $\mathrm{~B}\left(100^{\circ}\right)$ & $\begin{array}{l}\text { Paraesthesia C5-T1, } \\
\text { brachial plexus }\end{array}$ & $\begin{array}{l}\text { Musculocutaneous/ } \\
\text { radial/axillary (motor) }\end{array}$ & None & 6 \\
\hline Grate, 2000 & M & 20 & $\mathrm{U}\left(110^{\circ}\right)$ & Tingling sensation (fingers) & None & GTF & $\mathrm{N} / \mathrm{R}$ \\
\hline $\begin{array}{l}\text { Davids and Talbott, } \\
1990\end{array}$ & M & 29 & $\mathrm{U}$ & Numbness C5-T1 (arm) & None & HSL & 1 \\
\hline Rae and Sylvester, 1988 & $\mathrm{~F}$ & 34 & $\mathrm{U}$ & Brachial plexus (3 cords) & $\begin{array}{l}\text { Slight disability } \\
\text { (hand) }\end{array}$ & None & 12 \\
\hline
\end{tabular}

Abbreviations: M: male; F: female; Y: years; U: unilateral; B: bilateral; MBA: motorbike accident; MVA: motor vehicle accident; N/R: not reported; SCNF: superficial cutaneous nerve of the forearm; GTF: great tuberosity fracture; RCT: rotator cuff tear; OEF: open elbow fracture; HSL: Hill-Sachs lesion; F-U: follow-up.

countertraction" method, as described by Freundlich [12], or by a two-step technique, as described by Nho et al. [13]. Several complications are reported for inferior shoulder dislocation. Bone fractures, such as great tuberosity, inferior glenoid fossa, acromion, scapular spine, coracoid process, and/or soft tissue injuries, such as avulsed shoulder capsules, rotator cuffs tears, or ruptures of the adjacent muscles (supraspinatus, infraspinatus, teres minor, sunscapularis) are likely with inferior shoulder dislocations [14, 15]. Other complications are neurovascular compromise that may affect the brachial plexus (most commonly injury to the axillary nerve) and even an axillary vein causing thrombosis $[4,14,16]$.

Neurological injury after inferior shoulder dislocation was noted in 26 patients in previous reports (Table 2). In
19 patients, neurological symptoms were resolved 12 months after injury. Six patients experienced a persistent neurological deficit. No follow-up information was available for one patient who initially had radial paresthesia. Brachial plexus injuries are a well-recognized complication of inferior glenohumeral dislocation [1, 3, 17]. This is probably due to the final position of the humeral head in the axilla after the dislocation $[13,18]$. It seems that the axillary nerve was probably damaged more frequently (Table 2) $[1,4,7$, $11,18]$ due to its anatomic position close to the anterior aspect of the glenohumeral joint and its course around the neck of the humerus $[1,18]$. The nerve path makes it liable to be stretched or/and compressed due to the humeral head when the upper limb is forced in hyperabduction of proximal 
humerus accompanying by direct axial loading $[19,20]$. In our case report, the patient had persistent mild neurological symptoms in the distribution of the ulnar nerves after 18 months of shoulder reduction, without affecting the level of activities of daily living.

\section{Conclusion}

In conclusion, inferior shoulder dislocation requires careful clinical and radiographic evaluation and a high index of suspicion for associated injuries (bone, soft tissue, and neurovascular injuries). These injuries occur frequently and can be significantly associated with higher energy trauma. The prognosis is directly influenced by the early diagnosis and the successful reduction of shoulder dislocation. Although some authors have recommended immediate reduction followed by surgical repair of the associated injuries (such as rotator cuff), our patient achieved satisfactory functional recovery, according to the patient's demands, after immediate reduction and conservative treatment with physical therapy.

\section{Conflicts of Interest}

The authors declare no conflict of interest.

\section{References}

[1] A. Imerci, Y. Golcuk, S. G. Ugur, H. T. Ursavas, A. Savran, and L. Surer, "Inferior glenohumeral dislocation (luxatio erecta humeri): report of six cases and review of the literature," Turkish Journal of Trauma and Emergency Surgery, vol. 19, no. 1, pp. 41-44, 2013.

[2] S. Saseendar, D. K. Agarwal, D. K. Patro, and J. Menon, "Unusual inferior dislocation of shoulder: reduction by twostep maneuver: a case report," Journal of Orthopaedic Surgery and Research, vol. 4, no. 1, 2009.

[3] D. Owen, M. Nambiar, P. Moore, and M. Thomas, "Luxatio erecta humeri with neurovascular compromise: inferior glenohumeral dislocation illustrating associated injuries," BMJ Case Reports, vol. 2016, 2016.

[4] G. I. Groh, M. A. Wirth, and C. A. Rockwood, "Results of treatment of luxatio erecta (inferior shoulder dislocation)," Journal of Shoulder and Elbow Surgery, vol. 19, no. 3, pp. 423-426, 2010.

[5] L. Camarda, U. Martorana, and M. D'Arienzo, "A case of bilateral luxatio erecta," Journal of Orthopaedics and Traumatology, vol. 10, no. 2, pp. 97-99, 2009.

[6] P. J. Rae and B. S. Sylvester, "Luxatio erecta-two cases without direct injury," Injury, vol. 19, no. 5, pp. 361-362, 1988.

[7] K. Hamdi, T. M. Amine, B. Sofien, M. Thabet, N. Nader, and A. M. L. Ben, "Inferior dislocation of the shoulder complicated with brachial plexus palsy: a case report," Journal of Musculoskeletal Disorders and Treatment, vol. 4, no. 3, 2018.

[8] Y. Demirtas, A. O. Yildirim, H. Tirin, Ö. F. Öken, and A. Uçaner, "A rarely seen shoulder dislocation: luxatio erecta," Journal of Orthopedics, Traumatology and Rehabilitation, vol. 9, no. 1, pp. 65-67, 2017.

[9] I. Grate, "Luxatio erecta: a rarely seen, but often missed shoulder dislocation," The American Journal of Emergency Medicine, vol. 18 , no. 3, pp. 317-321, 2000.
[10] P. Ellanti, N. Davarinos, M. J. Connolly, and H. A. Khan, "Bilateral luxatio erecta humeri with a unilateral brachial plexus injury," Journal of Emergencies, Trauma, and Shock, vol. 6, no. 4, pp. 308-310, 2013.

[11] F. Yao, L. Zhang, and J. Jing, "Luxatio erecta humeri with humeral greater tuberosity fracture and axillary nerve injury," The American Journal of Emergency Medicine, vol. 36, no. 10, pp. 1926.e3-1926.e5, 2018.

[12] B. D. Freundlich, "Luxatio erecta," Journal of Trauma, vol. 23, no. 5, pp. 434-436, 1983.

[13] S. J. Nho, C. C. Dodson, K. F. Bardzik, R. H. Brophy, B. G. Domb, and J. D. MacGillivray, "The two-step maneuver for closed reduction of inferior glenohumeral dislocation (luxatio erecta to anterior dislocation to reduction)," Journal of Orthopaedic Trauma, vol. 20, no. 5, pp. 354-357, 2006.

[14] K. Petty, J. Price, M. Kharasch, and J. Novack, "Bilateral luxatio erecta: a case report," Journal of Emergency Medicine, vol. 46, no. 2, pp. 176-179, 2014.

[15] H. Sharma and F. Denolf, "Atypical subglenoid inferior glenohumeral dislocation clinically mimicking anterior dislocation," European Journal of Trauma, vol. 30, no. 4, 2004.

[16] C. A. X. Acosta, E. da Silva Resch, and R. Rodrigues, "Bilateral luxatio erecta, a case report," Revista Brasileira de Ortopedia, vol. 47, no. 1, pp. 130-132, 2012.

[17] J. Davids and R. Talbott, "Luxatio erecta Humeri," Clinical Orthopaedics and Related Research, vol. 252, pp. 144-149, 1990.

[18] A. C. Fox and D. R. Martin, "Up in arms: bilateral luxatio erecta fracture-dislocations," American Journal of Orthopedics (Belle Mead NJ), vol. 45, no. 6, pp. E328-E330, 2016.

[19] H. Cift, S. Soylemez, M. Demiroglu, K. Ozkan, V. E. Ozden, and A. T. Ozkut, "Rare inferior shoulder dislocation (luxatio erecta)," Case Reports in Orthopedics, vol. 2015, 3 pages, 2015.

[20] K. S. Kumar, "Hands up: a case of bilateral inferior shoulder dislocation," Emergency Medicine Journal, vol. 18, no. 5, pp. 404-405, 2001. 